\title{
ELECCIONES Y TRANSICIÓN DEMOCRÁTICA EN MÉXICO (1976-2012)
}

José Antonio Crespo*

RESUMEN: El autor ofrece un equilibrado análisis de los procesos electorales en México, desde 1976 hasta el 2012. Luego de revisar las crisis de fin de sexenio en tiempos del PRI monolítico, describe las distintas estrategias seguida por Salinas, Zedillo, y Fox; examina la problemática e incierta elección presidencial del 2006 y concluye con una valoración de la reciente elección del 2012.

$$
\text { sose }
$$

ABSTRACT: In this article, the author provides a well-balanced analysis of the Mexican electoral processes from 1976 to 2012. After revisting the recurrent end-of-term crisis during the PRI regime, the author describes the different political strategies employed by Salinas, Zedillo, and Fox, explains the troublesome and uncertain 2006 presidential election, and concludes with an evaluation of the 2012 election.

PALABRAS ClAVE: México, elecciones, democracia, crisis, PRI, PAN, PRD.

KEY WORDS: Mexico, elections, democracy, crisis, PRI, PAN, PRD.

RECEPCIÓN: 17 de septiembre de 2012.

APROBACIÓN: 26 de septiembre de 2012.

* Profesor-investigador del Centro de Investigación y Docencia Económicas, CIDE. 


\section{ELECCIONES Y \\ TRANSICIÓN \\ DEMOCRÁTICA \\ EN MÉXICO (1976-2012)}

\section{Introducción}

Las elecciones han constituido la ruta por la cual México ha transitado hacia la democracia, lo cual no representa sino uno de los elementos constitutivos de tal régimen político: el acceso al poder. El otro tiene que ver más con el ejercicio del poder. En lo primero, el acceso al poder, una democracia se distingue del autoritarismo por contemplar al menos dos opciones reales de poder, que compiten en condiciones de equidad y libertad tales que no determinen el resultado previamente, y la decisión final es tomada por los electores por medio de su voto. En lo que toca al ejercicio del poder, la democracia se distingue por contar con mecanismos que permitan remover a quienes disponen de poder formal (incluido el jefe de gobierno) en caso de que incurra en una grave trasgresión legal o abuso de poder, por vía pacífica, legal e institucional. En contraste, en los autoritarismos, dicha posibilidad es imposible, por lo cual la remoción del poder de algún gobernante abusivo se hace sumamente difícil (prevalece la impunidad institucional), y exige, en el extremo, la movilización externa de las instituciones vigentes de un amplio sector de la población (lo que es típico en una revolución), con altos costos sociales, humanos y económicos.

En México hemos avanzado significativamente en lo primero, pero muy poco, si acaso, en lo segundo. Por la vía de elecciones esencialmente competitivas, libres y equitativas, se ha podido ir transforman- 
do el régimen, de autoritario a democrático, al menos en lo que hace al acceso al poder. Desde luego, ha habido dudas e inconformidades, así como ajustes periódicos al marco normativo e institucional en materia electoral, que han permitido experimentar dos alternancias pacíficas a nivel presidencial (en 2000, y en 2012), sin recurrir a la violencia o con graves riesgos a la estabilidad. Eso no había ocurrido en toda la historia del país. El proceso no ha estado exento de desafíos y tropiezos, casi inevitables en todo proceso de democratización, pero hasta ahora han sido superados. Y en esa medida, los riesgos de inestabilidad política también se han ido reduciendo.

\section{Crisis cíclicas de fin de sexenio}

Al menos desde 1976, el país ha sufrido una crisis de fin de sexenio, aunque con distinta intensidad y por diferentes motivos. En ese año, lo mismo que en 1982, las crisis tuvieron esencialmente un origen económico, pero golpearon fuertemente la legitimidad del régimen priísta, debilitándolo significativamente. Eso mismo creó las condiciones para que el tradicional control político de corte autoritario se empezara a di-

84 ficultar. En 1988 hubo también una crisis de fin de sexenio, igualmente con tintes económicos, pero fundamentalmente de origen político, enmarcada por una ruptura grave del PRI en 1987, y la consecuente candidatura de Cuauhtémoc Cárdenas, por quien votaron numerosos segmentos del régimen descontentos con el nuevo modelo económico adoptado por Miguel de la Madrid, llamado genéricamente "neoliberalismo", que implicó una política de austeridad y la reducción de los privilegios económicos para los líderes de los sectores corporativos del PRI, andamiaje esencial del régimen posrevolucionario. ${ }^{1}$ Varios de ellos, o sus agremiados, sin abandonar el PRI, sufragaron por Cárdenas, dándole un caudal de votos que pudo haberlo hecho ganar la elección (lo cual quedó incierto) y que orilló al gobierno en turno a cometer un monumental fraude electoral, hoy reconocido por todos (aunque en ese año Grijalbo.

${ }^{1}$ Cfr. Luis Javier Garrido, La ruptura; la Corriente Democrática del PRI, 1993, México, 
muchos sostuvieron que no hubo tal fraude o, si acaso, que no fue tan grande como para poner en duda la legitimidad del triunfo del candidato oficial, Carlos Salinas de Gortari). Contó también el fortalecimiento del PAN, sobre todo a raíz de la crisis de 1982, que generó descontento en amplios sectores de clase media, que orientaron su voto y respaldo hacia el blanquiazul, así como la llegada a ese partido de importantes empresarios, molestos con la estatización de la banca que arbitrariamente decidió José López Portillo durante su último informe presidencial (1982). ${ }^{2}$ Las dos oposiciones ya fortalecidas, el PAN, y la encabezada por Cárdenas (quien fue postulado por un amplio frente de partidos de izquierda), generaron la crisis electoral de ese año, con un conflicto que puso en riesgo la estabilidad social, si bien Cárdenas decidió no convocar a sus partidarios a la confrontación y apostó a cristalizar su movimiento en un nuevo partido político, el de la Revolución Democrática (PRD).

El gobierno de Salinas de Gortari terminó también en una crisis política que desencadenó otra de tipo económico, sumamente severa. La aparición pública de la guerrilla chiapaneca a principios de 1994 afectó el proceso electoral y desató una dinámica política en medio de la cual se dio el asesinato del candidato oficial, Luis Donaldo Colosio (sustituido por Ernesto Zedillo), y poco después, del secretario general del PRI, José Francisco Ruiz Massieu. Las salidas de capital durante ese año redujeron al límite las reservas internacionales lo cual, aunado a un mal manejo de una inevitable devaluación monetaria, provocó una crisis económica más grave aún que la de $1982 .^{3}$

Frente a todos esos antecedentes, el presidente Zedillo comprendió que no había ya condiciones para prolongar la tradicional hegemonía del PRI, por lo que aceptó una amplia apertura política, dio un paso decisivo a un sistema electoral cabalmente competitivo. ${ }^{4}$ Eso, y la marcada tendencia a la baja de la votación del PRI, provocaron en 1997 la pér-

${ }^{2}$ Cfr. Soledad Loaeza, El Partido Acción Nacional, la larga marcha; 1939-1994, 1999, México, Fondo de Cultura Económica.

${ }^{3}$ Cfr. José Antonio Crespo, Urnas de Pandora; partidos y elecciones en el gobierno de Salinas, 1995, México, Espasa-Calpe.

${ }^{4}$ Cfr. José Antonio Crespo, ¿Tiene futuro el PRI?; entre la supervivencia y la desintegración total, 1998, México, Grijalbo. 
dida de la mayoría absoluta de ese partido en la Cámara Baja del Congreso, así como del gobierno de la capital, y tres años después, la presidencia de la República. Zedillo comprendió que la viabilidad del modelo económico de su preferencia se pondría en riesgo de no abrir de par en par el sistema electoral y partidista, pues ello supondría tensar nuevamente la cuerda de la estabilidad política. Prefirió exponer el poder de su partido (por lo cual fue considerado como un traidor por sus correligionarios) que arriesgar la estabilidad del país. La alternancia consecuente, a favor del PAN, abrió una enorme oportunidad para consolidar la democracia electoral y profundizar ese régimen en otros ámbitos (como el indispensable de la rendición de cuentas). Y también representó, por primera vez en mucho tiempo, un fin de sexenio sin crisis política ni económica, precedente que debió ser repetido para fortalecer la frágil y no garantizada democratización del país. Sin embargo, el primer gobierno emanado de la oposición, por diversas razones no favoreció esa tendencia y en cambio generó condiciones que dieron lugar a una nueva crisis de fin de sexenio, esta vez exclusivamente políticoelectoral. ${ }^{5}$ Una crisis que podría tener perjudiciales secuelas políticas y sociales, dado el rijoso clima de polarización que precedió la elección presidencial y que se intensificó una vez celebrada.

\section{La estrategia frente a las oposiciones: ¿cerrazón o apertura?}

Para entender estas crisis cíclicas hay una variable (entre muchas) de tipo político que resulta clave: la estrategia hacia las oposiciones, ubicadas a la derecha e izquierda del PRI. El punto de partida es un principio general de la política democrática (o semi-democrática): cuando se abren los canales institucionales a la oposición y la disidencia, éstas tienden a moderarse (que no es lo mismo que claudicar a su causa); si en cambio se cierran u obstruyen dichos canales, la oposición y la disidencia tienden a radicalizarse. Y la radicalización de las oposiciones en pleno traspaso del poder gubernamental incrementa la probabilidad de que

${ }^{5}$ Cfr. Alejandra Lajous, Vicente Fox; el presidente que no supo gobernar, 2007, México, Océano. 
se genere una crisis política, que puede afectar o no la economía, considerando además que en todo régimen político la sucesión del poder genera riesgos y tensiones que pueden poner en riesgo la estabilidad política. Y es que la pugna por el poder moviliza a diversos grupos sociales, económicos y políticos que desean ocupar directamente el poder o influir decisivamente sobre quien recaerá. Lo que está en juego es mucho, por lo cual, si las reglas para dirimir esta sucesión no están sólidamente fortalecidas, entonces la sucesión política se vuelve sumamente conflictiva, e incluso conlleva el riesgo de desatar las hostilidades entre los contendientes y sus partidarios. Mal manejada la sucesión podría dar lugar a disturbios, un golpe de Estado, una revolución o una guerra civil. ${ }^{6}$ Ejemplos de ello sobran, lo mismo en la historia universal que en la de México.

Las crisis políticas de fin de sexenio deben también enmarcarse en el agotamiento gradual de la institucionalidad política del régimen priísta, que había logrado resolver perfectamente el problema de la sucesión del poder sexenalmente, aunque mediante reglas claramente autoritarias. Cuando dichas reglas se fueron agotando (lo mismo dentro del PRI como en relación a la oposición), los riesgos de conflictividad durante cada sucesión del poder gubernamental tendieron a incrementarse. Por eso hubo graves crisis políticas en las sucesiones posteriores a la revolución (1920, 1923, 1928, 1929), y en la etapa final del régimen priísta (1988 y 1994). Al principio se debió a la fragilidad de la nueva institucionalidad (reglas y procedimientos), y al final, por su agotamiento. ${ }^{7}$

Volviendo al la forma en que los distintos gobiernos enfrentaron a la oposición partidista, según el cual la apertura genera moderación y la cerrazón, radicalismo, hagamos un breve repaso de cómo se manejó esto en los últimos años, ya en el ámbito de la transición política. José López Portillo (1976-1982) experimentó el agotamiento del régimen de partidos y de la legitimidad política del régimen, que se tradujo

${ }^{6} \mathrm{Cfr}$. Samuel Huntington, El orden politico en las sociedades en cambio, 1972, Buenos Aires, Paidós.

${ }^{7}$ Cfr. José Antonio Crespo, Los riesgos de la sucesión presidencial; actores e instituciones rumbo al 2000, 1999, México, Centro de Estudios de Política Comparada. 
en que fue candidato único por la presidencia (lo que desproveía al régimen de sus atuendos democráticos, exponiéndolo como partido prácticamente único), por lo cual instrumentó en 1979 una reforma política (aunque no plenamente democrática) que ofreció mejores condiciones de competencia a la oposición, incorporando a grupos y partidos de la izquierda histórica (marxista y revolucionaria) hasta entonces excluidos del sistema de partidos. ${ }^{8}$ Es decir, aplicó una estrategia de apertura hacia las oposiciones de derecha e izquierda, que se tradujo en su moderación, revigorizando además el sistema de partidos y arrojando una nueva bocanada de legitimidad sobre el régimen. Por lo cual, en 1982 no hubo conflictividad político-electoral, sino incluso gran pluralidad con varios candidatos en contienda. ${ }^{9}$ La crisis, ese año, respondió a variables fundamentalmente económicas.

El sucesor de López Portillo, Miguel de la Madrid (1982-1988), echó reversa a la apertura política, pese a haberla ofrecido como compensación a la austeridad económica que se imponía, por el temor que le suscitó el fortalecimiento de la oposición. El PAN ganó presencia y alcaldías importantes sobre todo en el norte del país (Ciudad Juárez, Chihuahua, San Luis Potosí, Durango), lo que impulsó a De la Madrid a detener ese avance por medio del tradicional recurso al fraude electoral (claramente en Durango y Chihuahua, en 1986). ${ }^{10}$ Se tradujo en una postura radicalizada de los panistas, que en 1988 postularon como candidato presidencial a un líder carismático y temerario, salido de las filas empresariales: Manuel Clouthier. Por su parte, la izquierda, desde su incorporación a la lucha electoral en 1979, se había moderado ideológica y estratégicamente (abandonando la retórica marxista, la hoz y el martillo, la internacional socialista), pero no sumaba más del $5 \%$ de la votación. ${ }^{11}$ No representaba un desafío real al régimen. Sin embargo, la inconformidad dentro del PRI tradicional (nacionalista-

\footnotetext{
${ }^{8}$ Cfr. Octavio Rodríguez Araujo, La reforma politica y los partidos en México, 1979, México, Siglo XXI.

${ }^{9} \mathrm{Cfr}$. Juan Molinar, El tiempo de la legitimidad; elecciones, autoritarismo y democracia en México, 1991, México, Cal y Arena.

${ }^{10}$ Cfr. Juan Molinar, "Regreso a Chihuahua”, Nexos, núm. 111, marzo de 1987.

${ }^{11} \mathrm{Cfr}$. Arturo Anguiano, Entre el pasado y el futuro; la izquierda en México, 1969-1995, 1997, México, Universidad Autónoma de México.
} 
revolucionario), consecuencia de las políticas neoliberales de De la Madrid, generó una grave ruptura en el partido hegemónico (la última había tenido lugar en 1952), permitiendo aglutinar a la izquierda histórica en torno a la candidatura de Cuauhtémoc Cárdenas, quien también captó el respaldo de segmentos priístas afectados por el neoliberalismo. La reacción del gobierno ante la disidencia dentro del PRI (la Corriente Democrática), fue de cerrazón, lo que precipitó la ruptura y radicalización de ese movimiento. ${ }^{12}$ Así, la elección presidencial de 1988 enfrentó dos movimientos opositores fuertes y radicales, lo que orilló al régimen a recurrir a un magno fraude electoral con el consecuente conflicto político. En otras palabras, De la Madrid, por temor al crecimiento de la oposición, practicó la política opuesta de López Portillo; en lugar de la apertura, la cerrazón. Y obtuvo los efectos contrarios a los de la apertura lópez-portillista: radicalismo y conflictividad. ${ }^{13}$

Carlos Salinas de Gortari (1988-1994) entendió parcialmente las lecciones de 1988. Por un lado, entabló una alianza integral con el PAN, cuyo programa económico era compatible con el neoliberalismo abanderado por De la Madrid y fortalecido por el propio Salinas. A cambio, se reconocerían algunos de los triunfos incontestables del PAN a nivel regional (contrariamente a lo ocurrido en 1986), por lo cual se reconocieron victorias panistas a nivel de gubernatura en Baja California (1989), Guanajuato (1991) y Chihuahua (1992), así como varias plazas municipales de importancia. El resultado de dicha apertura fue la moderación del panismo. De modo tal que, por el flanco derecho, Salinas siguió una estrategia similar a la de López Portillo, con efectos estabilizadores.

Sin embargo, dicha apertura fue parcial ("selectiva", se le llamó), pues no se aplicó en el caso de la pujante izquierda. Salinas, además de sentirse agraviado dado que su triunfo fue escatimado y opacado por Cárdenas, temió el potencial político-electoral del PRD, por lo que su reacción fue de hostigamiento y cerrazón. Le aplicó el tradicional

${ }^{12}$ Cfr. Garrido, La ruptura ... op. cit.

${ }^{13}$ Cfr. Pablo González Casanova (coord), Segundo Informe sobre la democracia en México; el 6 de julio de 1988, 1990, México, Siglo XXI. 
fraude, arrebatando una posible victoria del PRD, al menos en el Congreso de Michoacán (origen regional del neocardenismo) en 1989, y tres años después en la contienda por la gubernatura. Puede decirse que Michoacán en 1992 tuvo efectos similares en el PRD que los del PAN por Chihuahua y Durango en 1996. El resultado fue una mayor radicalización del PRD y de algunos grupos sociales con él identificado. Si bien dicha estrategia se tradujo en el debilitamiento electoral del PRD (obtuvo $9 \%$ de la votación en los comicios intermedios de 1991), por eso mismo se intensificó la movilización de los grupos de izquierda extra-institucionales. Uno de ellos fue el Ejército Zapatista de Liberación Nacional (EZLN), quien al irrumpir en 1994 justificó su recurso a las armas a partir de que, por el lado de la izquierda, se habían cerrado los canales institucionales, a diferencia de lo ocurrido respecto de la derecha, lo cual era exacto. En otras palabras, la apertura de Salinas hacia el PAN se tradujo en la moderación de éste, pero la cerrazón hacia el PRD se tradujo en la radicalización de la izquierda (partidista y social), lo que le complicó la sucesión presidencial, provocando una nueva crisis política y económica. ${ }^{14}$

Ernesto Zedillo (1994-2000) entendió cabalmente esa lección y decidió que, para conjurar las crisis de fin de sexenio, era menester abrir los canales institucionales, no sólo al PAN sino también al PRD. ${ }^{15}$ Por ello aceptó la plena autonomía y nuevas facultades a las autoridades electorales: el Instituto Federal Electoral (IFE) y el Tribunal Electoral del Poder Judicial de la Federación (TEPJF). También impulsó una nueva ley electoral plenamente competitiva (1996), y se dispuso a aceptar todo triunfo que legítimamente ganara la oposición, lo mismo del PAN que del PRD. ${ }^{16}$ El PAN continuó ganando nuevas plazas, como las de Jalisco, Querétaro y Nuevo León. Al PRD le fue reconocida una importante victoria en el gobierno de la capital (1997), y más tarde en Zacatecas (producto de una nueva ruptura dentro del PRI). Esto se tradujo en

${ }^{14} \mathrm{Cfr}$. Crespo, Urnas de Pandora ... op. cit.

${ }^{15} \mathrm{Cfr}$. José Antonio Crespo, Jaque al rey; hacia un nuevo presidencialismo en México, 1996, México, Joaquín Mortiz.

${ }^{16}$ Cfr. José Woldenberg, Ricardo Becerra y Pedro Salazar, La reforma electoral de 1996; una descripción general, 1997, México, Fondo de Cultura Económica. 
moderación política no sólo del PAN, sino también del PRD (con la consecuente pérdida de influencia de los movimientos extremistas de ese polo del espectro ideológico, incluido el EZLN). Esto preparó políticamente el terreno a una sucesión presidencial ordenada y civilizada que, además, se tradujo en la primera alternancia pacífica del poder (que favoreció al candidato del PAN, Vicente Fox). Desde luego, tampoco hubo una crisis económica, sino que el país registró en ese año un inusual crecimiento económico del 7\%. La ya tradicional crisis de fin de sexenio fue evitada.

\section{La opción estratégica de Fox}

Vicente Fox (2000-2006) llegó con la mayor legitimidad democrática y electoral registrada en la historia. Pero no continuó con la política de apertura democrática iniciada por su antecesor, sino que, por diversas razones (y probablemente de forma inconsciente) aplicó a la oposición la estrategia seguida por Salinas de Gortari: apertura a una parte de ella (el PRI, en este caso, a quien se le extendió una carta de impunidad buscando su cooperación para aprobar reformas estructurales en materia económica), y creciente cerrazón y hostigamiento a otra parte de la oposición (el PRD, nuevamente). Las razones de ello no están del todo claras y pueden haber sido diversas: a) el riesgo de que un eventual ascenso al poder del PRD trastocara la política neoliberal (que también Fox siguió); b) una rivalidad personal entre el precandidato más fuerte de ese partido y jefe de gobierno de la capital, Andrés Manuel López Obrador; c) el temor de que López Obrador, no muy proclive a la negociación pragmática con sus rivales, desde la presidencia llamara a cuentas a Fox y su esposa por presuntos actos de corrupción e ilícito enriquecimiento familiar. Cualquiera de estas razones, o todas en combinación, podrían explicar la decisión de Fox para poner trabas en el camino de López Obrador a Los Pinos, quien casi desde el principio empezó a encabezar las encuestas de preferencia electoral.

A fines de 2003 se registró ya un suceso que auguraba posibles dificultades para la elección de 2006; el Instituto Federal Electoral (IFE), 
que había cobrado en sus últimos años gran prestigio y credibilidad, perdió el consenso partidista que le había dado fuerza y funcionalidad tanto en 1994 como en 1996 (fechas en que se renovó el Consejo General de esa institución). El consenso partidista supone que al menos los tres partidos más importantes validen y den un voto de confianza a los miembros del Consejo General del IFE. Pero en 2003, al renovarse una vez más el Consejo General, el PRD quedó fuera del proceso, lo que dio un grave golpe a la credibilidad del instituto. La izquierda perredista se sintió injustamente marginada en ese procedimiento (tanto el PRI como el PAN pudieron haberlo evitado), y negó dar un voto de confianza al nuevo Consejo General del IFE. El proceso de radicalización del PRD empezó a resurgir a partir de entonces.

Poco más adelante, surgieron varios videos que mostraban movimientos de corrupción de algunos funcionarios del gobierno capitalino, lo que implicaba un fuerte golpe político a López Obrador. El problema consistió en que el manejo y divulgación de tales videos tuvo como eje al gobierno federal, en combinación con personajes como el senador panista Diego Fernández de Cevallos, y el ex presidente Carlos Salinas de Gortari. La injerencia en ello del poder Ejecutivo implicaba el uso del Estado, su aparato y recursos para incidir sobre la contienda políticoelectoral, lo cual rompe una de las reglas básicas del juego democrático (pues contra los recursos del Estado es imposible competir). En otras palabras, el nuevo gobierno emanado del PAN empezaba a incurrir en la práctica que desde la oposición condenó: no respetar los principios básicos de la democracia electoral. Y eso fue tomado por la izquierda como la ruptura del acuerdo democrático que se pactó bajo el gobierno de Zedillo y que fue respetado en lo esencial por éste.

El asunto del llamado "video-escándalo" no logró bajar a López Obrador en las encuestas decisivamente. Entonces el gobierno federal aprovechó una falta menor del gobierno capitalino para emprender un nuevo embate político; había desacatado una orden judicial al no despejar la maquinaria utilizada para hacer un camino en una propiedad privada, que comunicaría un hospital. El camino no se hizo pero la orden de remover la maquinaria tardó algunas semanas, por lo cual 
el gobierno decidió solicitar al Congreso el desafuero de López Obrador, para penalizarlo. Aquello implicaría su posible remoción de la contienda presidencial en 2006. Los diputados del PAN y el PRI acordaron desaforar a López Obrador, pese a no hacer lo mismo con los corruptos líderes petroleros del PRI, cuya falta en el llamado Pemexgate involucraba cerca de 1,500 millones de pesos desviados ilícitamente para la campaña del PRI en 2000.

La opinión pública, en su mayoría (hasta el $80 \%$ según varias encuestas), se inclinó a ver el desafuero de López Obrador bajo la óptica del PRD (una maquinación política para sacarlo de la contienda presidencial), más que bajo la versión del gobierno federal (la estricta aplicación de la ley ante una falta administrativa menor). Eso, y una intensa movilización de diversos grupos ciudadanos (que incluyó una mega-marcha de más de un millón de asistentes en el centro de la capital), orillaron a Fox a desistir de su estrategia, dando marcha atrás mediante una opción jurídica cuya viabilidad meses atrás había negado (con lo cual confirmó en los hechos que, en efecto, el desafuero no era la única alternativa legal, sino que tenía una clara intencionalidad política) ${ }^{17}$

La estrategia del desafuero fue diseñada y operada de manera burda, por lo cual resultó contraproducente a los objetivos esperados. Peor aún, la izquierda lo interpretó como una nueva muestra de que había una decisión del gobierno federal de detener el avance de López Obrador, echando mano de los recursos del Estado (en este caso, la Procuraduría General de la República). Se veía como un desconocimiento de Fox del acuerdo democrático forjado durante el sexenio anterior, con lo cual se empezó a dar una polarización social y política y la radicalización de la izquierda, pues sentía - no sin fundamento- que los canales institucionales se le obstruían una vez más (como en el gobierno de Salinas de Gortari). Pese a que el candidato del PRD seguía gozando de gran ventaja en las encuestas electorales, la izquierda sabía que enfrentaría una fuerte resistencia por parte del gobierno federal y otros actores políticos, cuyos intereses podrían ser afectados ante una even-

${ }^{17}$ Cfr. Jorge Castañeda y Rubén Aguilar, La diferencia: radiografía de un sexenio, 2007, México, Grijalbo. 
tual llegada de López Obrador a la presidencia. Y bajo ese clima político, polarizado, enrarecido, rijoso, escaso en confianza electoral y con una izquierda crecientemente radicalizada, se llegó al proceso electoral. La política de Fox hacia la oposición fue muy similar a la seguida por Salinas de Gortari (hostigar y bloquear al PRD), por lo que terminó su gobierno con una crisis política en lugar de seguir la estrategia de Zedillo (abrir el juego político a todas las oposiciones y dejar a la ciudadanía tomar la elección final en las urnas), que terminó su sexenio en medio de civilidad, consenso y estabilidad.

\section{6: una elección incierta}

Debe decirse que los intentos de Fox por detener a López Obrador no hubieran impedido el triunfo del perredista, dada la enorme ventaja que todavía en marzo registraba en las encuestas (cerca del 10\%), de no haber cometido graves errores que mermaron esa ventaja de manera dramática. López Obrador descuidó una regla fundamental en los comicios democráticos: el llamado "voto duro", formado por los partidarios incondicionales (o casi), gustan de un discurso radical y extremista. Pero dado que con ese segmento no es posible ganar una elección, se requiere contar con el voto de otros sectores más moderados e independientes, que en México conforman entre el 40 y $45 \%$ del electorado; se distinguen en que su respaldo no es incondicional, no gustan de las expresiones radicales ni la estridencia discursiva y no tienen mayor problema en cambiar de preferencia o simplemente alejarse de las urnas. En marzo, López Obrador aventajaba por al menos 10 puntos a Felipe Calderón, candidato del PAN y su principal adversario. El voto obradorista estaba formado mayoritariamente por independientes, que sin embargo se fueron alejando en los últimos meses ante sus errores, la soberbia de darse por ganador anticipadamente y su estridencia discursiva. El radicalismo en el discurso del candidato del PRD, que incluía una descalificación indiscriminada a los grupos empresariales, y que culminó con insultos estridentes al presidente Fox, le abrió un hueco que permitió a sus rivales (en particular el PAN) presentarlo creíblemente como "Un peligro para México" (según rezaba una de las con- 
signas en la publicidad panista), un líder populista o un "Mesías tropical". ${ }^{18}$ En otras palabras, por dar gusto a su base dura (una minoría ya convencida) descuidó a sus electores independientes. Así ocurrió y los independientes se redujeron significativamente. Justo en marzo, López Obrador contaba con $40 \%$ de independientes frente al 22\% que apoyaba a Calderón. Pero al mes siguiente, ya sólo $29 \%$ de independientes continuaba con el tabasqueño, en tanto que Calderón atraía al 25\%. ${ }^{19}$ Al finalizar la campaña, ya sólo $35 \%$ de independientes estaba con López Obrador, frente a $31 \%$ que se alinearon con Calderón. ${ }^{20}$

Pero ese no fue el único error del candidato del PRD. También haber decidido no asistir al primero de dos debates presidenciales. Suele ocurrir que el candidato que lleva la ventaja arriesga en un debate y son sus rivales los que más tienen que ganar en esos encuentros. Al plantearse el primer debate, López Obrador se hallaba aún muy por encima de sus seguidores, por lo cual decidió no asistir y reservarse simplemente para el segundo debate. Además, en el momento en que se celebró ese primer debate, era ya un hecho el descenso del candidato perredista en las encuestas. ${ }^{21}$ Finalmente, debe señalarse también como un error haber decidido no aparecer en los medios, por una medida de austeridad que hipotéticamente el ciudadano recompensaría en las urnas. En principio quizá sí, pero cuando se es objeto de una fuerte y eficaz campaña negativa conviene más responder puntual y oportunamente y no dejar que lo dicho por el adversario quede como una verdad no desmentida. Así pues, López Obrador repitió algunos de los errores cometidos por Cuauhtémoc Cárdenas durante la campaña de 1994, de cuyos tropiezos no fue capaz de extraer las lecciones pertinentes para no tropezar con las mismas piedras con que topó Cárdenas doce años atrás. ${ }^{22}$ Esos errores minaron gravemente las preferencias electorales de López Obrador, al grado de que las últimas encuestas previas

${ }^{18}$ Así lo denominó el historiador Enrique Krauze en un ensayo publicado en su revista Letras Libres.

${ }^{19}$ Encuesta de El Universal, abril de 2006.

${ }^{20}$ Encuesta de salida de Consulta Mitofsky, julio de 2006.

${ }^{21}$ Cfr. Lajous, Vicente Fox, el presidente... op. cit., pp. 384-407.

${ }^{22}$ Adolfo Aguilar Zínzer, ;Vámos a ganar! La pugna de Cuauhtémoc Cárdenas por el poder, 1995, México, Océano, p. 142. 
a los comicios, reflejaban un "empate técnico" con Calderón, lo que supone que cualquiera de estos dos contendientes podía ganar y seguramente lo haría por un margen estrecho.

Puede decirse que la elección presidencial de 2006 representó un fracaso en tanto que no pudo generar consenso sobre el resultado o la convicción generalizada de que, quien ganó oficialmente -Felipe Calderón-, fue la opción de la mayoría de los electores. Las elecciones democráticas diseñan sus reglas y condiciones para elevar la probabilidad de que dicho consenso se dé, pues en esa medida, es más factible que la pugna por el poder se dirima de manera pacífica y civilizada, se proteja la estabilidad política, se fortalezcan las instituciones públicas y las autoridades emanadas del proceso gocen de plena legitimidad. Al no haber consenso electoral, todo ello se logra en menor medida o, en el extremo, se llega a perder. Desde luego, una elección organizada democráticamente no garantiza que se alcance ese consenso; simplemente eleva significativamente la probabilidad de que ello ocurra. Pero toda institución humana es falible y también lo son las elecciones, incluso de contar con un formato democrático. Por eso mismo, países con gran tradición y solidez democrática pueden experimentar también dudas e impugnaciones sobre los resultados oficiales, como ocurrió en Estados Unidos en el año 2000, o en Alemania e Italia en 2005 y 2006, respectivamente.

La mayor equidad en la contienda, la imparcialidad de las autoridades que organizan y califican los comicios, así como la pulcritud del proceso electoral son elementos que contribuyen a obtener el consenso electoral (y por ende, la aceptación del veredicto por parte de los perdedores). Pero no siempre es posible garantizar tales condiciones, o mejor dicho, casi nunca lo es. Siempre quedará algún remanente en cuanto a la equidad, imparcialidad o pulcritud; los partidos gobernantes suelen gozar de alguna ventaja por el solo hecho de serlo. Tampoco es posible evitar por completo que los contendientes intenten incidir sobre la votación incurriendo en conductas ilícitas, cuando no ilegales. No puede presumirse una perfecta organización, limpia de anomalías, sean éstas resultado de errores humanos, del diseño de la boleta o de la forma de ser llenada; fallas en el conteo o bien producto de acciones do- 
losas, aisladas u orquestadas. Y aun en caso de que no hubiera mala fe, los errores y anomalías pueden opacar la claridad del resultado, de ser éste sumamente cerrado, como lo fue en 2006 (233, 831 votos de ventaja para el ganador, es decir $.56 \%$ de la votación total).

De lo que se trata en una democracia electoral es, entre otras cosas, de reducir las condiciones para que ocurra todo ello, con el propósito de que esas inevitables anomalías o inequidades no se vuelvan determinantes en el resultado final. Cosa que, sin embargo, se dificulta si la distancia entre el ganador oficial y su más cercano seguidor es muy reducida, pues en tal caso ese pequeño número de irregularidades -así sean errores humanos y no actos dolosos- pueden nublar la certeza del veredicto final. En otras palabras, si bien es verdad que una regla de la democracia electoral es que "por un voto se gana o se pierde" (lo cual es cierto dependiendo del sistema electoral en cuestión), un corolario lógico de ello es que, en tal circunstancia, "basta un voto dudoso o irregular para que no sea posible determinar con certeza quién ganó". Es decir, mientras más cerrado es un resultado, más limpia, equitativa y transparente debe ser la elección, para que un veredicto estrecho genere, pese a todo, consenso y credibilidad entre los participantes y sus respectivos partidarios. De lo contrario, surgirán la incertidumbre, la duda, la impugnación, el cuestionamiento sobre la credibilidad en la elección misma y la legitimidad de su ganador oficial. Y por eso, una reducida ventaja para quien obtiene el primer sitio puede hacer que las inequidades, errores, inconsistencias, incluso si son de una magnitud relativamente pequeña, puede afectar la claridad del resultado al grado de no poderse saber con certeza quién fue el ganador de la contienda.

En una elección sumamente cerrada, para que el veredicto final quede libre de toda duda -al menos a los ojos de la mayoría ciudadanadebe ser impecable, impoluta de toda irregularidad, inequidad o errores de escrutinio y cómputo, lo cual no ocurre ni en las democracias más desarrolladas. De hecho, tampoco fue muy distinto el nivel de anomalías en la elección de 2000, considerada como la más democrática de la historia de México. La magnitud de errores de captación fue de 1.26\% de votos por casilla en 2000 , y $1.35 \%$ en $2006 .{ }^{23}$ La diferencia consistió

${ }^{23}$ Cfr. Javier Aparicio, "La evidencia de una elección confiable", Nexos, núm. 346, octubre 2006, pp. 49-53. 
pues, en el margen de victoria, de más de $6 \%$ en 2000 y de casi .6\% en 2006. Esas inconsistencias y errores, tanto en el 2000 como en el 2006, no fueron producto de un magno operativo para torcer la voluntad ciudadana, o al menos no se puede concluir a partir de la distribución de esas anomalías. ${ }^{24}$ Como quiera, tales inconsistencias fueron suficientes en 2006 (a diferencia de lo ocurrido seis años antes) para arrojar dudas razonables sobre quién ganó en realidad. Precisamente por ello, las autoridades electorales pudieron y debieron haber puesto todo su empeño en hacer lo más transparente y exhaustivo posible el proceso de escrutinio y cómputo de los votos -en el que se registraron múltiples inconsistencias, fuesen o no dolosas. ¿Pudieron el Instituto Federal Electoral (IFE) y el Tribunal Electoral del Poder Judicial de la Federación (TEPJF) hacer un mayor esfuerzo por transparentar el proceso de escrutinio y cómputo de la votación? Sin duda.

Por eso mismo, está previsto en la ley electoral que el IFE realice una segunda revisión de las actas y lleve a cabo el cómputo oficial de la elección por parte de un Consejo Distrital (uno por cada distrito electoral, que son 300). Estos Consejos tienen como responsabilidad - entre otrasrealizar el cómputo de la elección mediante las actas correspondientes a su distrito, y en los casos que prevé la ley, están facultados para abrir los paquetes electorales y proceder al recuento de las boletas ahí contenidas. El número de actas con inconsistencias aritméticas fue de aproximadamente 83 mil, es decir, el 65\% del total. El IFE decidió abrir y recontar sólo 2,873 paquetes, es decir, apenas un 3.5\% del total de paquetes cuyas actas registraban inconsistencias (un promedio de 9 paquetes por distrito). En muchos distritos, el número de actas abiertas fue sumamente reducido, incluso nulo, como se percibe en el Cuadro 1.

\section{CUADRO 1}

Número de distritos donde se abrieron y recontaron tres o menos paquetes electorales

\begin{tabular}{lcccccccc}
\hline Paquetes abiertos & 0 & 1 & 2 & 3 & 4 & 5 & 6 & Total \\
Número de distritos & 22 & 29 & 32 & 24 & 24 & 24 & 24 & 155 \\
\hline
\end{tabular}

${ }^{24}$ Fernando Pliego, El mito del fraude electoral en México, 2007, México, Editorial Pax, cap. V. 
En 107 de los 300 distritos (es decir, poco más de una tercera parte), se abrieron y recontaron 3 o menos paquetes, y en 155 de los distritos (más de la mitad) se recontaron 6 paquetes o menos, frente a un promedio de 275 actas inconsistentes por distrito (es decir, en más de la mitad de distritos se abrió 1 de cada 45 paquetes cuyas actas registraban inconsistencias aritméticas). Eso mismo generó acusaciones de parcialidad del IFE por parte del PRD, pues la estrategia seguida por el PAN era justo abrir el menor número posible de paquetes electorales. El IFE no debía de abrir ni más ni menos paquetes que aquellos que ordenaba la ley, pero abrió sólo el 3.5\% de los que debió haber recontado.

Ante esta situación y la consecuente inconformidad del PRD, ¿cuál fue la respuesta del Tribunal Electoral? Una primera sentencia sobre la elección presidencial fue emitida por el TEPJF el 5 de agosto de 2006, en la que aborda la forma y los criterios en que el IFE realizó el recuento oficial, el 5 de julio del mismo año. ${ }^{25}$ El Tribunal reprendió al IFE por haber dejado sin revisar tantos paquetes cuyas actas mostraban inconsistencias (cerca de 80 mil actas, es decir, 96\% de las que debían revisarse). Y eso tenía que hacerlo de oficio, es decir, que para hacer dicha apertura "no se requiere petición de los partidos políticos". El Tribunal reclamó la falta de exhaustividad al IFE, lo que implicaba que el IFE descuidaba el "máximo beneficio posible que se pudiera alcanzar en el procedimiento de depuración del recuento de la votación". ${ }^{26}$

Llegado a este punto, el TEPJF pudo haber instruido al IFE la reposición del procedimiento bajo la presencia del propio Tribunal, o bien pudo ordenar la revisión de las actas inconsistentes que no fueron revisadas por el IFE, para lo cual también tiene atribuciones, de acuerdo a una tesis de jurisprudencia en la que se lee:

A efecto de alcanzar el objetivo de certeza, rector del sistema de justicia electoral, se prevé como una atribución del órgano jurisdiccional electoral federal la de ordenar, en casos extraordinarios, la realización de alguna diligencia judicial, como sería la apertura de los paquetes electorales... (aunque ello) constituye una medida última, excepcional

${ }^{25}$ TEPJF: Expediente: Sup-Jin/212-2006 y otros, op. cit., 5 de agosto de 2006.

${ }^{26}$ TEPJF: Sup-Jin/212-2006 y otros, op. cit., 5 de agosto de 2006. 
y extraordinaria que únicamente tiene verificativo cuando, a juicio del órgano jurisdiccional, la gravedad de la cuestión controvertida así lo exige, su eventual desahogo pudiera ser de trascendencia para el sentido del fallo -como ocurriese si pudiese ser determinante para el sentido de la elección- y (cuando) sólo se pueda alcanzar certidumbre a través de tal diligencia. ${ }^{27}$

Pero en lugar de ordenar la depuración de inconsistencias requerido para imprimir certeza en el resultado, el Tribunal ordenó abrir sólo una proporción reducida de los paquetes que quedaban aún sin revisar: 11,718 casillas, que corresponde al 15\% de las actas inconsistentes. En total, entre el IFE y el Tribunal se recontaron 14, 594 los paquetes electorales abiertos, aproximadamente el 18\% de las más de 83 mil actas que registraban errores aritméticos de manera evidente, y que el Cofipe estipula que debían ser recontadas de oficio, de acuerdo a la interpretación que hizo el propio Tribunal. Eso, pese a que los observadores electorales de la Unión Europea recomendaban justo el recuento total para disipar toda duda y que en ese mismo sentido se manifestaba buena parte de la prensa extranjera. Según encuestas, alrededor de un $72 \%$ de los ciudadanos veía bien la revisión de todas las casillas para imprimir mayor certeza al resultado de la elección. ${ }^{28}$

La decisión del Tribunal de revisar sólo una pequeña proporción de paquetes electorales fue tomada por el PRD como una señal de parcialidad de los magistrados electorales, pues coincidía con la estrategia del PAN. El propio equipo de Felipe Calderón, y él mismo, reconocieron posteriormente que lo que más les convenía era abrir el menor número de paquetes electorales posible, pues en realidad no sabían bien a bien qué contenían esos paquetes, por lo que un recuento amplio podía arrebatarles el triunfo que ya tenían en las manos. El propio Calderón narró que en un primer momento consideró que sería positivo el recuento para su causa, pues podría darle más credibilidad a un triunfo del que él mismo no dudaba. El 10 de julio, es decir, días después del recuen-

27 "Paquetes electorales. Sólo en casos extraordinarios se justifica su apertura ante el órgano jurisdiccional”, Compilación Oficial de Jurisprudencia y Tesis Relevantes 1997-2005, 2005, México, TEPJF, p. 211 (cursivas mías).

${ }^{28}$ Cfr. Excélsior-Parametría, 28 de Julio de 2006. 
to oficial del IFE, cuenta: "Reuní a mi equipo y dije "vamos al recuento. No tengo la menor duda'. Es más, probablemente un recuento hubiera dado más votos, porque si alguien hizo trampa fue el PRD en el D.F... Yo no tenía preocupación". ${ }^{29}$ Sin embargo, miembros de su equipo lo convencieron de que un recuento podría implicar el riesgo de mayores anomalías que las detectadas hasta entonces; "efectivamente, si hubiéramos ido a un recuento en ese momento de desorden, lo que hubiera sacado el PRD es un argumento político para anular la elección". ${ }^{30}$

El Tribunal no debía, en efecto, respaldar en los hechos ni la estrategia del PAN ni la del PRD, sino hacer lo que la ley le facultaba para buscar la máxima certidumbre posible. Al quedar más del 80\% de actas inconsistentes sin revisar por ninguna autoridad, el PAN obtuvo un triunfo estratégico. Pero, evidentemente, eso dejó sin despejar la incógnita sobre cuántas inconsistencias aritméticas que no pudieran ser justificadas ni depuradas (votos irregulares) quedaron en las actas, y si su número sería tal que opacara la certeza del resultado. De acuerdo a la lógica que rige la normatividad electoral, si el número de votos irregulares no justificables iguala o supera la cantidad de sufragios con que el primer lugar aventaja al segundo, no es posible saber cuál fue la voluntad del electorado. Así, una tesis de jurisprudencia señala que:

No es suficiente la existencia de algún error en el cómputo de los votos para anular la votación recibida en la casilla impugnada, sino que es indispensable que aquél sea grave, al grado de que sea determinante en el resultado que se obtenga, debiéndose comprobar por tanto, que la irregularidad revele una diferencia numérica igual o mayor en los votos obtenidos por los partidos que ocuparon el primero y segundo lugares en la votación respectiva. ${ }^{31}$

¿Qué sucedería si dicha situación se diera también a nivel nacional, es decir, que el número de votos irregulares, no justificados ni depurados,

${ }^{29}$ Citado por Salvador Camarena y Jorge Zepeda Patterson, El presidente electo, 2007, México, Planeta, p. 187.

${ }^{30}$ Apud Camarena y Zepeda, op. cit., p. 187.

31 "Error grave en el cómputo de votos. Cuándo es determinante para el resultado de la votación", Compilación Oficial de Jurisprudencia y Tesis Relevantes 1997-2005, 2005, México, TEPJF, p. 116. 
superase a los 233,831 sufragios con que Calderón aventajó oficialmente a López Obrador? Pues, al igual que en las casillas anuladas por el Tribunal, se violentaría la certeza en el recuento de votos. No se podría saber, en otras palabras, cuál fue la voluntad del electorado ni, por tanto, quién fue el legítimo ganador.

El Tribunal, en su dictamen final, señaló que el número de inconsistencias fue debidamente justificado en su mayoría, y que las que no lo fueron no superaban la ventaja con la que oficialmente Calderón aventajó a su más cercano seguidor. Por lo cual, la certeza del resultado estaba fuera de duda. Sin embargo, al revisar las actas de 150 de los 300 distritos electorales, resulta que los votos irregulares plenamente justificados no constituyeron una mayoría, y los no justificados superan la diferencia que oficialmente se adjudicó a Calderón sobre López Obrador. Así, los votos irregulares contabilizados fueron 365, 995, pero de ellos 49,456 estuvieron plenamente justificados a partir de los criterios establecidos por el Tribunal Electoral, quedando entonces 316, 539 votos irregulares sin justificar. Esos votos irregulares en sí mismos rebasan los 233, 831 con que Calderón superó oficialmente a López Obrador. La proyección de esos votos irregulares a 300 distritos rebasan los 600 mil. ${ }^{32}$ Es decir, lo que prevalece según las actas oficiales de escrutinio y cómputo no reflejan un triunfo claro e inequívoco de Felipe Calderón, tal como lo afirmó el Tribunal Electoral en su dictamen final, sino la imposibilidad de saber con certeza cuál fue la voluntad del electorado. Por eso era importante llevar a cabo un recuento mucho más amplio del que se hizo, al menos de aquellos paquetes cuyas actas eran inconsistentes (el 63\% del total), para así imprimir certeza electoral al reducirse los votos irregulares por debajo de la diferencia entre primero y segundo lugar. En tal caso, hubiera sido posible generar el mayor consenso en torno al resultado y mayor legitimidad para el ganador oficial. Pero, debido a que no fue así, podemos bautizar la de 2006 como una "elección incierta".

La reacción de López Obrador fue, de nuevo, poco institucional. Primero ordenó un plantón en paseo de la Reforma por seis semanas,

${ }^{32}$ Cfr. José Antonio Crespo, 2006: hablan las actas, 2008, México, Random House Mondadori. 
afectando a un buen número de ciudadanos, tanto en el tráfico como en el comercio de esa importante zona capitalina. También desconoció el veredicto del Tribunal, faltando a una regla básica de la democracia electoral: aceptar el veredicto del árbitro máximo, incluso si se le considera como injusto. De lo contrario, los objetivos de la democracia electoral se pondrán en riesgo. ${ }^{33} \mathrm{Y}$ de ahí la importancia de incorporar a los contendientes tanto en la formulación de las reglas como en la selección de árbitros. Si bien en el nombramiento del IFE quedó fuera el PRD (lo cual, como se dijo, fue un elemento de impugnación), no fue el caso respecto del TPJF, cuyos magistrados fueron nombrados por consenso de todos los partidos. Al desconocer el resultado oficial, y tras haber mandado "al diablo" a las instituciones (según su propia expresión), tuvo la ocurrencia de hacerse investir frente a sus seguidores como "Presidente legítimo", todo lo cual podría provocar que los electores independientes que aún habían votado por él ese año se le alejaran en alguna proporción, dificultando su eventual triunfo en los comicios de 2012, en caso de volver a contender por la presidencia. Cosa que, en efecto, ocurrió.

\section{2: el retorno del PRI y el nuevo litigio poselectoral}

El nuevo presidente, Felipe Calderón (2006-2012), tomó una postura frente a la oposición más parecida a la de Ernesto Zedillo que a la de Vicente Fox. Pese al desconocimiento que hizo el PRD de su triunfo, optó por mantener una posición de apertura y diálogo tanto con ese partido como con el PRI (que respaldó su triunfo, facilitando con ello la gobernabilidad durante su gobierno), lo que en principio debía traducirse en un fin de sexenio y un traspaso del poder tranquilo y civilizado en 2012. No ocurrió exactamente así, pues ante el triunfo del PRI en ese año (una nueva alternancia, pero en sentido inverso a la del año 2000), el candidato del PRD (y sus aliados partidarios, el Partido del Trabajo y el Movimiento Ciudadano), López Obrador, mantuvo su posición radical de

${ }^{33}$ Cfr. Christopher Anderson, André Blais, Shaun Bowler, Todd Donovan y Ola Listhaug, Losers ' Consent: Elections and Democratic Legitimacy, 2005, Oxford, Oxford University Press. 
no reconocer el resultado oficial ni a su ganador como presidente legítimo. Pero eso no podría atribuirse ya, al menos no en ese año, a la cerrazón gubernamental, sino a la decisión del líder tabasqueño de mantener una estrategia de confrontación frente al gobierno y de cuestionamiento a las autoridades electorales, pese a que en 2007 y 2008 se modificó significativamente el marco normativo e institucional de los comicios. Dicha reforma incorporó varias de las demandas que la izquierda había exigido (como la utilización de tiempos oficiales para desplegar la publicidad partidaria y de campaña, en lugar de ser directamente contratado con los medios electrónicos de comunicación). También, se sustituyó anticipadamente al Consejo General del IFE, permitiendo, ahora sí, la participación del PRD en la propuesta y nombramiento de los consejeros electorales (que incluso hizo la propuesta formal de quien ocupó la presidencia del Instituto para los comicios de 2012).

López Obrador logró hacerse nombrar nuevamente candidato presidencial, orillando a su principal contendiente, Marcelo Ebrard (jefe del gobierno capitalino), a hacerse a un lado para no provocar una ruptura en la izquierda. El candidato perredista arrancó su campaña en tercer lugar en las encuestas, mostrando además un elevado número de los llamados "negativos" (electores que "jamás votarían por un candidato", en este caso, el tabasqueño), probable producto de su desconocimiento del veredicto en 2006 y de los actos de protesta y su autonombramiento como "presidente legítimo" en ese año. En contraste, el candidato del PRI, el exgobernador del Estado de México, Enrique Peña Nieto, iniciaba con gran ventaja en esas mismas encuestas. La candidata del PAN, Josefina Vázquez Mota, que se hallaba en segundo sitio, enfrentaba ya una gran decepción de lo que habían significado los gobiernos de su partido, muy por debajo de las expectativas despertadas en el año 2000. López Obrador, más conciente de la necesidad de contar con el voto independiente, dio un giro de 180 grados en su tradicional discurso de confrontación institucional y polarización social, apelando a la instauración de lo que llamó una "República amorosa", lo que le atrajo un importante segmento de votantes independientes que, además, recelaban mayoritariamente de un retorno del PRI al poder. Eso le permitió escalar al segundo sitio y acortar 
significativamente la distancia que lo separaba originalmente del candidato priísta, pero los votantes independientes no fueron suficientes para darle el triunfo a López Obrador. En marzo de 2012, todavía 45\% de los independientes apoyaba a Peña Nieto, en tanto que López Obrador convocaba apenas al $26 \%$ de ese segmento. ${ }^{34}$ El día de la elección, el 41\% de independientes votó por López Obrador frente al 32\% que lo hizo por Peña Nieto. ${ }^{35}$ Una gran hazaña haber arrebatado esa proporción de independientes a Peña durante la campaña, pero no fue suficiente para ganar la presidencia. Se explica porque el voto duro del PRD es mucho menor que el correspondiente al PRI (16\% frente a $28 \%$, respectivamente); no basta con contar con la mayoría del voto independiente para ganar la elección. Se hubiera requerido una proporción aún mayor de ese votante para lograr el triunfo. La distancia con la que triunfó Peña Nieto respecto de López Obrador fue de $6.6 \%$ de la votación (catorce veces más que la diferencia con que ganó Calderón seis años atrás).

Sin embargo, López Obrador tampoco reconoció el resultado en esta ocasión, alegando inequidad en la competencia, así como ilícitos que, según él, decidieron la elección a favor del abanderado priísta. Pero tal reclamo era más difícil de sostener que en 2006 pues, como se dijo, cuando un resultado es sumamente cerrado, cualquier nivel de irregularidades, incluso uno pequeño, puede ser determinante; pero cuando la distancia es holgada, los ilícitos deben ser enormes para modificar un veredicto. Y si es el caso, deben ser debidamente sustentados y comprobados. El candidato perredista no reclamó el triunfo para sí, pero solicitó que se invalidara la elección, pues a su juicio se habían violentado principios constitucionales relativos a la elección. Pero, de acuerdo a la jurisprudencia electoral vigente, dicha violación tendría que ser grave, generalizada y determinante en el resultado, lo cual, dada la distancia de casi 7 puntos entre primero y segundo lugar, no era fácil demostrar. La coalición de izquierda señaló como principal causa de invalidación el sobregasto de campaña en que el PRI habría incurrido. Algo más que probable, pero que, según la legislación vigente aprobada por todos

${ }^{34}$ Encuesta de Reforma, marzo de 2012.

${ }^{35}$ Encuesta de salida de Reforma, julio de 2012. 
los partidos (incluidos los de izquierda), no era causal de nulidad sino sólo una falta administrativa sancionable con multas económicas. Y justo por eso, los tiempos para revisar los gastos de campaña no ajustaban con el plazo para calificar la elección, sino que lo sobrepasaban. Además, la instancia oficial para la investigación pertinente era el IFE, por lo cual el Tribunal no podía iniciar una investigación paralela a la del IFE ni adelantar conclusiones en tiempos menores para determinar si había o no afectación tan grave que ameritara invalidar la elección. El Tribunal señaló, en todo caso, que respetaba la voluntad del legislador (es decir, el Congreso) en sentido de que el sobregasto de campaña no podría ser motivo para anular una elección.

La otra denuncia más importante hecha por la izquierda fue que hubo una compra masiva del voto, que resultaba determinante en el resultado; si el PRI había ganado por una ventaja de 3 millones 300 mil sufragios, López Obrador señaló que hubo alrededor de cinco millones de votos comprados, que por ende resultaban determinantes en el resultado. Pero, para la exigencia de anulación a partir de esa denuncia habían algunos problemas: a) las pruebas presentadas no permitían demostrar nada, pues se trataba de cuatro mil (no cinco millones) de objetos con propaganda impresa o grabada del PRI, que constituyen regalos que lícitamente todos los partidos pueden -y suelen- ofrecer en sus mítines y actos de campaña, además de un puñado de animales de granja que cuantitativamente tampoco demostraban la magnitud acusada de votos presuntamente comprados; b) si bien condicionar dinero, bienes o programas sociales a votar por un partido o candidato es un delito sancionable con cárcel, difícilmente puede demostrarse que en efecto dicho intento culmina con el voto así comprometido. Y es que, como en otros países democráticos, se considera como suficiente antídoto contra la compra o coacción del voto el secreto para emitirlo, en cuyo caso el elector puede decidir libremente su sufragio, para quien intentó comprárselo o por cualquier otro partido. Ese argumento fue refrendado por el Tribunal, pero curiosamente había sido validado también por el propio López Obrador durante la campaña, cuando exhortaba a sus simpatizantes a recibir toda dádiva que se les ofreciera, pero a votar según su 
convicción, lo que era posible gracias a la secrecía del voto. Una causal de nulidad perceptible sería, en todo caso, la violación al secreto del voto, siempre y cuando fuese determinante resultado. Pero fue infinitesimal el número de casillas donde ese derecho no se garantizó. c) Desde el punto de vista lógico, resultaba al menos extraño que se denunciaran cinco millones de votos exclusivamente en la elección presidencial, pues no habían afectado los comicios legislativos, mismos que no fueron impugnados por la izquierda. ${ }^{36}$

Finalmente, la izquierda apeló a otros ilícitos o inequidades, como la probable compra ilícita de tiempos oficiales por parte de Peña Nieto para su publicidad, como el presunto uso propagandístico de las encuestas, todas las cuales acertaron en definir al priísta como ganador, pero muchas lo hicieron por un porcentaje mucho mayor del que en realidad ocurrió. Lo primero supone también una infracción administrativa, sancionable económicamente, pero no una causal de nulidad (ante la imposibilidad de determinar si los votos así conseguidos son determinantes en el resultado), y lo segundo no puede ser considerado como un acto doloso, premeditado o producto de una compra de todas las encuestadoras por parte del ganador (cuando, además, la mismas encuestadoras anunciaban el apabullante triunfo del PRD en la capital, como ocurrió).

Con todo, López Obrador logró implantar en buena parte de ciudadanos (principalmente sus seguidores) la duda sobre la limpieza de la elección y fidelidad de los resultados. Según una encuesta poselectoral, 71\% consideraba que hubo compra de votos, 59\% que el proceso no fue limpio, y 53\% no creía que hubiera prevalecido la equidad. Sin embargo, $55 \%$ pensaba que el fallo del TEPJF, validando la elección, fue la correcta (aunque un no despreciable $36 \%$, consideraba que dicho fallo no era adecuado). ${ }^{37} \mathrm{La}$ explicación más probable de esa aparente contradicción es que muchos ciudadanos podían pensar que hubo irregularidades, pero que éstas no fueron determinantes en el resultado como para invalidar la elección, dada la holgada diferen-

${ }^{36}$ TEPJF, Juicio de Inconformidad, Sup-Jin/359/2012.

${ }^{37}$ Encuesta telefónica de Reforma, septiembre de 2012. 
cia que en esta ocasión hubo entre primero y segundo lugar. Y es que, en efecto, las condiciones que prevalecieron en la elección de 2012 -descalificadas por muchos en la izquierda como las más sucias de la historiano fueron muy distintas a las que prevalecieron en la elección considerada como la más limpia de nuestra historia, la del año 2000. En 2012, la distancia entre primero y segundo lugar fue cercana a 7\% (poco más que en 2000), que en votos se traduce en 3 millones 3 mil (en 2000 fueron 2 millones 400 mil de diferencia entre primero y segundo lugar). La compra y coacción del voto nunca ha disminuido en nuestro país, según lo reflejan diversos informes de Alianza Cívica -organización de observación electoral por excelencia- a lo largo de estos años de democratización. El aparato del PRI estaba volcado en favor de su candidato, pues peligraba la presidencia. Y el PRI desvió 1,500 millones de pesos de Pemex. Por su parte, hubo el sistema de financiamiento paralelo conocido como Amigos de Fox, así como rebase de gasto de campañas. Igualmente, las encuestas fallaron en mayor medida que en 2012, pues la mayoría daba como ganador a Francisco Labastida. Y los medios mayoritariamente atacaban y descalificaban al candidato de la oposición, alejándose de cualquier equidad en la cobertura de la campaña. Nadie cuestionó esa elección, pese a que en 2012 incluso la nueva normatividad electoral (de 2007) había logrado mayor equidad y vigilancia que en la de 2000.

¿Por qué la distinta evaluación en 2000 y en 2012? Por las siguientes razones: 1) en 2000 quien perdía era el PRI, símbolo de la antidemocracia, y era la primera alternancia pacífica en toda nuestra historia. Evidentemente, había esperanzas de cambio y mejoría. En 2012, el PRI regresa, lo que genera rechazo en la mayoría de la población, así como el temor o convicción de que eso representaría el fin del experimento democrático. En 2000, 60\% de ciudadanos pensaba que, para tener democracia cabal, el PRI debía perder. Ese mismo porcentaje, en 2012, suponía que el PRI no podía ganar en comicios competitivos si no fuese con grandes (y determinantes) irregularidades de por medio. 2) En 2000 quien quedó en segundo lugar no impugnó el resultado; al PRI no le quedaba más remedio que resignarse y aceptar un resultado des- 
favorable (en parte porque el presidente Zedillo había aceptado la inevitabilidad de ese desenlace y reconoció de inmediato el veredicto). Y el PRD quedó en tercer lugar, muy por abajo del ganador. No hubiera sido raro que, de haber quedado en segundo sitio, hubiera impugnado el proceso y desconocido el resultado.

En ese sentido, puede decirse que la diferencia entre las democracias avanzadas y las rezagadas radica menos en las irregularidades o inequidades que pueda haber y más en la aceptación del resultado por los perdedores. Un ejemplo típico es el de Al Gore en el año 2000. Las medios habían anunciado una gran ventaja para George Bush en Florida, estado determinante en la elección. Gore ya había dicho a su rival por teléfono que aceptaría su derrota en ese momento. Su equipo le dijo que esperara, pues su programa preliminar registraba sólo 1500 votos de ventaja para Bush. Gore decidió impugnar los resultados por todas la vías legales. La Corte de Florida -de inclinación demócrata-determinó un recuento total en el estado que, conforme avanzaba, reducía la distancia entre los punteros. Cuando esa diferencia era de apenas 158 votos, la Suprema Corte Federal -de inclinación republicana- ordenó suspender el recuento para determinar si éste era legal. Tras las audiencias de rigor, la Corte decidió que el recuento ordenado en Florida sí era legal, pero que el tiempo para continuar con ese ejercicio... ¡se había agotado! Se comprobó también que la secretaria de gobierno en Florida había rasurado del padrón a 20 mil electores demócratas, pero eso no era causal de nulidad (y había que acatar es disposición legal). A diferencia de lo que suele creerse, tales irregularidades son habituales en ese país. Es simplemente que en algunas ocasiones dichos ilícitos son determinantes, como fue el caso en la elección de 2000. ${ }^{38}$ Pero Gore felicitó públicamente a Bush: "No estoy de acuerdo con la decisión de la Suprema Corte -dijo-, pero la acepto... por el bien de la unidad y el fortalecimiento de nuestra democracia".

En México conceder suele ser visto como claudicación de principios, traición a los seguidores, suicidio político o incluso como una posición

${ }^{38} \mathrm{Cfr}$. Tracy Campell, Deliver the Vote: A History of Election Fraud, an American Political Tradition, 1742-2004, 2005, New York, Carroll \& Graf Publishers. 
antidemocrática. Cuenta desde luego la personalidad de los candidatos, pero más importantes son los incentivos creados históricamente para aceptar o desconocer una derrota. Desde el origen mismo de la democracia norteamericana, los empresarios y líderes políticos que apoyaban a un candidato lo hacían hasta que se emitía el fallo oficial. Después, le condicionaban su respaldo futuro a que acatara el veredicto, poniendo fin al conflicto. $\mathrm{Y}$ es que a esos promotores no les convenía en absoluto la inestabilidad que podría derivarse de un desacato y la consecuente rebelión (armada o no). De ahí que los incentivos para conceder sean muy fuertes en ese país. Aquí sucede a la inversa: López Obrador tiene fuertes incentivos intrapartidistas para no reconocer su derrota; le permite presentarse no como perdedor, sino como víctima, lo cual le puede dar nuevo aire para mantener un liderazgo moral y fáctico en el ámbito de la izquierda. Pero también hay incentivos externos al partido. John Ackerman, por ejemplo, refleja que, para el obradorismo, acatar un fallo desfavorable representa una actitud antidemocrática y no a la inversa:

El problema principal con la democracia mexicana no es que algunos actores políticos no "acepten su derrota", sino que demasiados aceptan la impunidad y la complicidad como algo normal y cotidiano. La debilidad más importante de la cultura política del país no es la supuesta ausencia de una "cultura de la legalidad", sino una obediencia y respeto exagerados a los dictados de la autoridad. En 2006, el cuestionamiento de la legitimidad de la elección y del gobierno de Calderón fue a todas luces justificado, y además rindió frutos políticos muy importantes. ${ }^{39}$

Entre esos frutos, Ackerman lista los siguientes: reformas favorables a la izquierda en materia electoral, penal, de derechos humanos y transparencia. Sin la presión social derivada del no reconocimiento no se habrían dado tales avances. Además, la izquierda pudo frenar las reformas que no le gustaban, como la energética. Igualmente se logró remover prematuramente a Luis Carlos Ugalde, presidente del IFE en 2006. Sin embargo, una encuesta señaló que $26 \%$ consideraba que desconocer es democrático, en tanto que $61 \%$ pensaba que eso daña a la demo-

${ }^{39}$ John Ackerman, "El sendero de la inconfirmidad", Proceso, $1^{\circ}$ de septiembre de 2012. 
cracia, pese a reconocer irregularidades. ${ }^{40}$ Pese a todo, el compromiso con la institucionalidad en materia electoral sigue siendo mayoritario entre la ciudadanía, lo que permite continuar por esa ruta en busca de la consolidación de la democracia. Sin embargo, como se mencionó al principio, sigue pendiente la asignatura de la rendición de cuentas, así como el combate efectivo contra la corrupción y el fin de la impunidad en el país. Sin ello, difícilmente se podrá hablar de una democracia funcional en México.

${ }^{40}$ Encuesta telefónica de Reforma, septiembre de 2012. 
